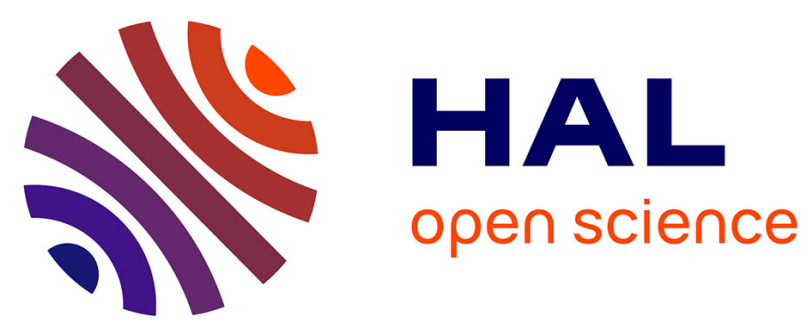

\title{
Analysis and prediction of single laser tracks geometrical characteristics in coaxial laser cladding process
}

\author{
Hussam El Cheikh, Bruno Courant, Samuel Branchu, Jean-Yves Hascoet, \\ Ronald Guillén
}

\section{- To cite this version:}

Hussam El Cheikh, Bruno Courant, Samuel Branchu, Jean-Yves Hascoet, Ronald Guillén. Analysis and prediction of single laser tracks geometrical characteristics in coaxial laser cladding process. Optics and Lasers in Engineering, 2012, 50 (3), pp.413-422. 10.1016/j.optlaseng.2011.10.014 • hal-01005246

\section{HAL Id: hal-01005246 \\ https://hal.science/hal-01005246}

Submitted on 29 Apr 2018

HAL is a multi-disciplinary open access archive for the deposit and dissemination of scientific research documents, whether they are published or not. The documents may come from teaching and research institutions in France or abroad, or from public or private research centers.
L'archive ouverte pluridisciplinaire HAL, est destinée au dépôt et à la diffusion de documents scientifiques de niveau recherche, publiés ou non, émanant des établissements d'enseignement et de recherche français ou étrangers, des laboratoires publics ou privés. 


\title{
Analysis and prediction of single laser tracks geometrical characteristics in coaxial laser cladding process
}

\author{
Hussam El Cheikh ${ }^{\mathrm{a}, *}$, Bruno Courant ${ }^{\mathrm{a}}$, Samuel Branchu ${ }^{\mathrm{a}}$, Jean-Yves Hascoët ${ }^{\mathrm{b}}$, Ronald Guillén ${ }^{\mathrm{a}}$

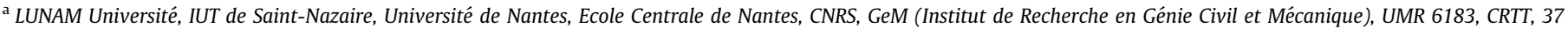 \\ boulevard de l'Université BP 406, 44602 Saint-Nazaire cedex, France \\ ${ }^{\mathrm{b}}$ Institut de recherche en Communications et en Cybernétique de Nantes (IRCCyN) UMR CNRS 6597, 1 rue de la Noë, BP 92101, F-44321 Nantes Cedex 03, France
}

\begin{abstract}
Direct Laser Fabrication is a promising new manufacturing technology coming from laser cladding process. From a coaxial nozzle, powder is fed through a laser beam on a substrate. The powder melting and solidification processes lead to the fabrication of a part layer by layer. In this work 316L stainless steel powder is used to form laser tracks on a low carbon steel substrate. The layer geometry is an important process characteristic to control the final part of fabrication. This paper presents analytical relationships between the laser tracks geometrical characteristics (width, height, area, penetration depth) and the processing parameters (laser power $P$, scanning speed $V$ and powder mass flow $Q_{m}$ ). Three values of each processing parameters are fixed and so 27 different experiments have been made and analyzed. The validity of these results is discussed studying the correlation coefficient $R$, the graphical analysis of the residuals and the uncertainty evaluations. Two kinds of models are studied to predict the form and the geometrical characteristics of the single laser tracks cross sections. The first one is an analytical model in which the distribution of the powder in the feed jet is supposed to govern the laser clad geometry. Three distributions are proposed: Gaussian, uniform and polynomial. In the second model the general form of the clad cross section is supposed to be a disk due to the surface tension forces. Analytical relationships are established between the radius and the center of the disk in one hand and the process parameters in the other hand. This way we show that we can reproduce the laser track geometry in all the area experimentally explored.
\end{abstract}

\section{Introduction}

Laser process techniques are used in many domains such as cutting, stamping dies, part repairing and rapid manufacturing [1-4]. Direct Laser Fabrication is an advanced process consisting of injecting some powder coaxially with a power laser beam in order to melt it and to form a clad after solidification (Fig. 1). The thickness of this layer is between 0.1 and $2 \mathrm{~mm}$. The mean goal of this technique is to build single real objects layer by layer with a complex 3D architecture. The pertinence of this new process and the dimensional precision of test parts have been studied according to the geometry complexity of the part and in comparison with other traditional techniques [5,6]. A wild range of different materials and metals can be used and a strong bonding between the substrate and the clad can be obtained [7]. It can also produce much better coatings than other techniques such as arc welding

\footnotetext{
* Corresponding author.

E-mail address: hussam.elcheikh@univ-nantes.fr (H. El Cheikh).
}

and thermal spray [8]. These advantages are very attractive for part manufacturing and metallic rapid prototyping.

Many works have been proposed to simulate the thermal field induced in a material by a moving laser beam during the 80 's and 90's [9-27]. In 2000s many authors used these models to simulate the DLF process. Picasso et al. [28] developed a simple geometrical model for laser cladding. Their model allows the laser beam velocity and the powder feed rate determination for a specified laser power, beam diameter and clad height. Toyserkani et al. $[29,30]$ use a transient three-dimensional finite element modeling, to show the dependence of many parameters in the laser cladding: The decrease of the laser beam velocity, or the increase of powder feed rate and the laser pulse energy, increases the clad height. A model of cross-section clad profile on the substrate in coaxial single-pass cladding with a low-power laser has been studied in [31]. Lalas et al. [7] take into account the process speed, the powder feed rate and the surface tension between the added material and the substrate for the estimation of the clad geometry. Oliveira et al. [32] present a theoretical and experimental study of the coaxial laser cladding process to understand the basic concepts of the process and understanding the relations between 


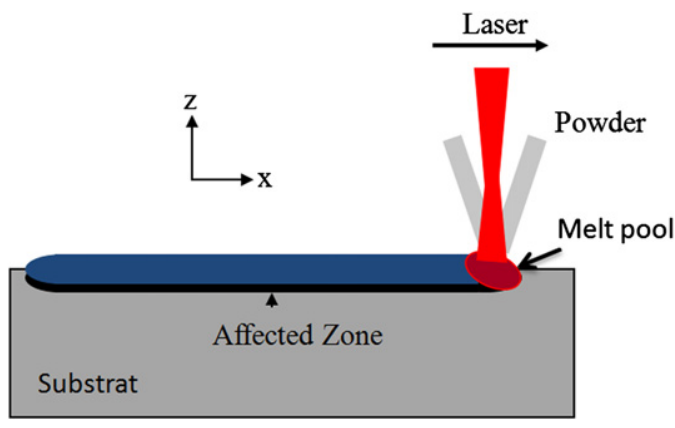

Fig. 1. Direct Laser Fabrication process.

the main coaxial laser cladding parameters and geometrical characteristics of an individual laser track. Bamberger et al. [33] developed an analytic one dimensional thermal model for estimation of depth of the molten bath and concentration of the alloying elements. Onwubolu et al. [34] investigate the prediction of the clad geometry in laser cladding using the response surface methodology and scatter search optimization technique. Based on the Gaussian mode of the powder distribution in the jet flow, Lin [35] suggests a simplified mode function to estimate the clad profiles in an edge joint. Liu and Li [36,37] presented a model to study the effects of process variables on wall thickness, powder primary efficiency and speed of forming a thin metallic wall in single-pass coaxial laser cladding. The static model of powder mass concentration distribution was defined as a Gaussian function. Chryssolouris works since a longtime about laser machining [38] and contributed to a better knowledge of the laser cladding process [39], including thermal effects [40].

The goal of this current article is to suggest a method to predict the laser track geometry knowing the process parameters and to determine if the powder distribution in the jet is a determining factor for the laser track geometry. At first analytical relationships are searched to link the laser layer height, width and cross-section's surface with the process parameters such as the laser beam power and velocity and the powder feed rate. These relations are validated by their high correlation coefficient and a graphical analysis of the residues. But a complete laser clad geometry description is more than these three factors. We first suppose that the powder distribution is the main parameter, which governs the laser clad geometry. The clad height, in this case, is supposed to be determined by the powder quantity, which falls in each point. In order to study the validity of this hypothesis we establish analytical functions to describe the clad geometry in the case of three theoretical powder distributions in the powder jet. These theoretical descriptions of the clad geometry are compared to our experimental results. At last, we propose the description of the clad cross-section geometry as a part of a disk and we show that we are able to simulate our experimental results in all the area experimentally explored with a good approximation.

\section{Experimental conditions}

We use a 5 axes high-speed machine, a $150 \mu \mathrm{m}$ fiber laser with $700 \mathrm{~W}$ power supply and a coaxial nozzle specially designed according to the laser beam characteristics. A carrier gas (Ar) flow, fixed at $3 \mathrm{l} / \mathrm{min}$, imports the powder while a secondary gas (Ar) flow, fixed at $5 \mathrm{l} / \mathrm{min}$, is shaping the powder stream. The carrier gas (Ar) is used in order to avoid any chemical reaction with the injected powder. The value of $5 \mathrm{l} / \mathrm{min}$ chosen for the shaping gas flow is a simple pragmatic choice recommended by the nozzle designer. This nozzle is also equipped with a cooling channel to dissipate heat. The beam analysis was carried out with the "FOCUS MONITOR" from PRIMES Gmbh. The laser Beam is scanned with a rotation pinhole (about $20 \mu \mathrm{m}$ in diameter). This pinhole takes a small part of radiation and 2 mirrors direct the signal to a detector. By scanning the laser beam layer by layer, the laser beam geometry and the spatial distribution of irradiance can be determined.

Fig. 2 shows the conic powder jet stream geometry under the nozzle. Horizontal and vertical image analyses are studied. On the upper part of the jet, the horizontal image analysis displays two distributions due to the coaxial form of the nozzle. From the powder focus plan only one distribution remains. Image analysis software is used to study the powder distribution in the jet counting on the light reflection. The obtained functions are not directly the powder distribution in the jet but rather a projection of this distribution. Nevertheless, it can be deduced that, in the focus plan, the powder distribution is an almost symmetrical Gaussian type distribution. The cone of powder analysis is made with a simple camera and a software to analyze the obtained images. The powder reflects the light and so the more bright the image the more numerous the powder grains in one direction.

The powder focus plan, at a distance $l(l=3.5 \mathrm{~mm})$ from the nozzle, is a disk with a diameter $d_{p}\left(d_{p}=0.6 \mathrm{~mm}\right)$. The distance work $L$ is fixed to $5 \mathrm{~mm}$. Under the powder focus plan the powder distribution remains a Gaussian type distribution. The distance between the focus plan and the substrate surface is given by $L-1$ $(=1.5 \mathrm{~mm})$ and in the interaction plan the powder stream is $2 \mathrm{~mm}$ in diameter. The laser beam is focused on the substrate surface while the focused plan for the powder stream is $5 \mathrm{~mm}$ above. Fig. 3 shows the distribution at the focus plan of the laser beam when the diameter is $0.53 \mathrm{~mm}$ and the analysis shows a uniform distribution.

The vertical line in Fig. 2a displays the distribution along the $z$ direction. As shown in the image analysis, the higher concentration of the powder stream is in the focus plan. The coaxial nozzle allows a perfect symmetry of the particles' distribution in the stream and very few particles outside the main trajectories.

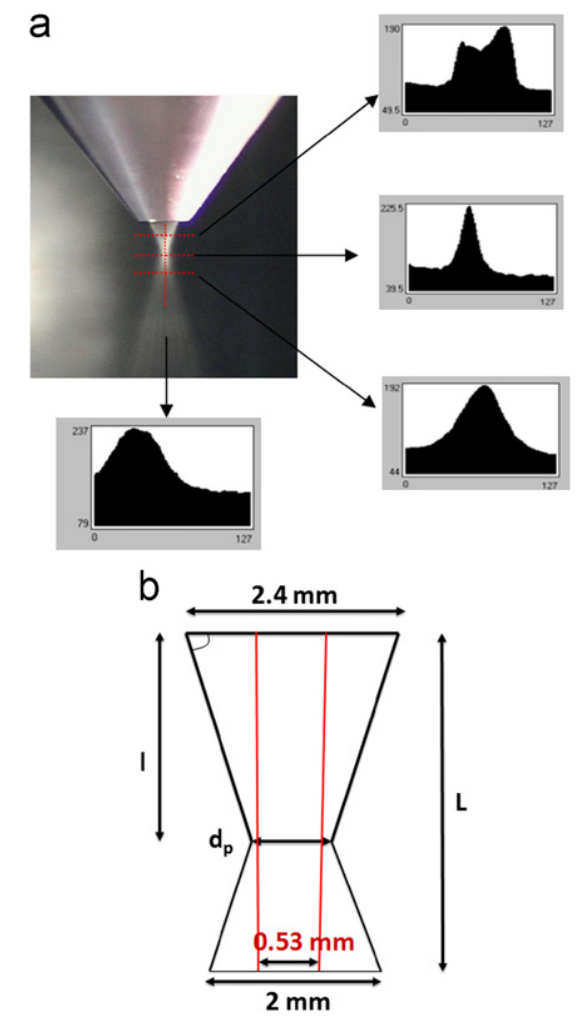

Fig. 2. (a) Powder stream pictures analysis. (b) Powder cone shape from the nozzle issue to the laser focused plan. 
a

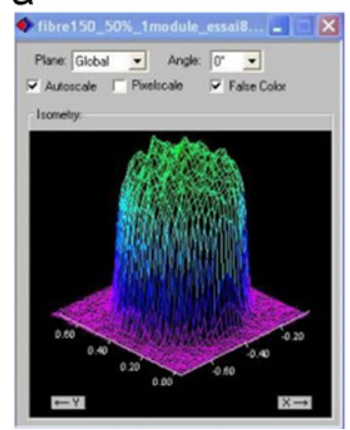

b

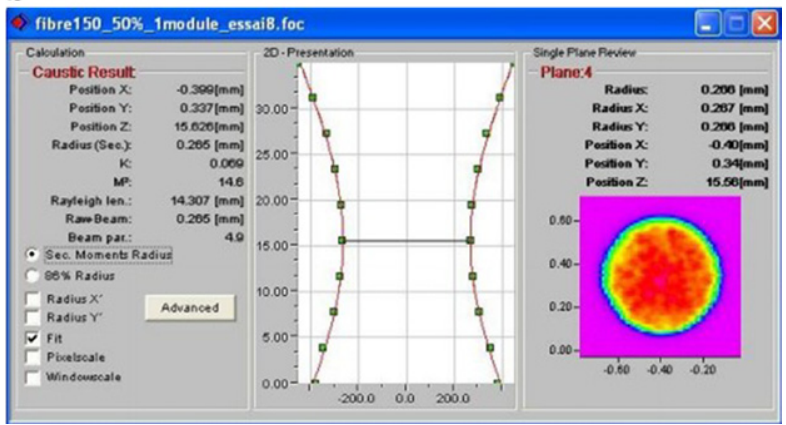

Fig. 3. Top hat laser beam analysis: (a) Spatial distribution of irradiance, (b) focalization plane determination and divergence of the laser beam.

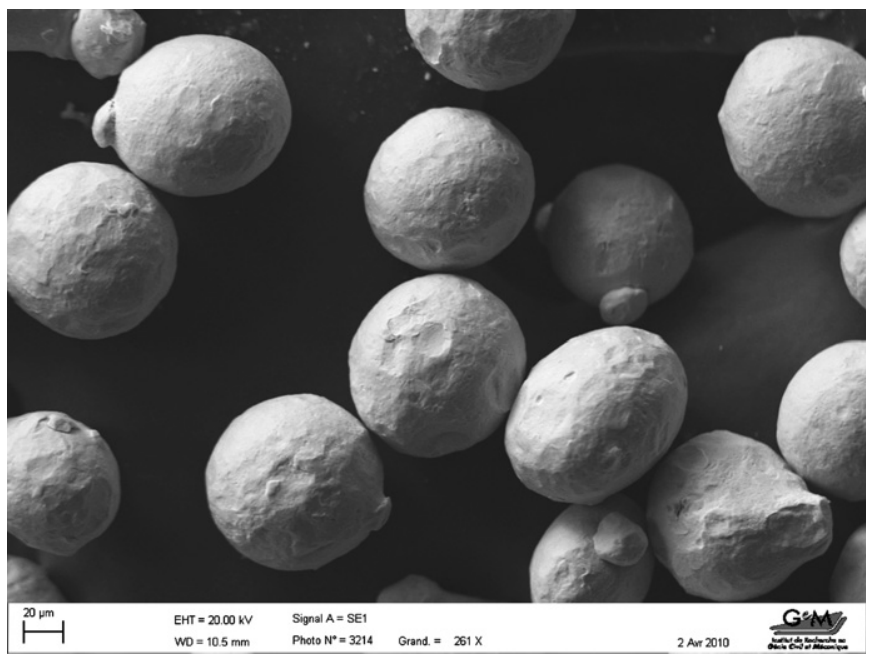

Fig. 4. 316L Powder.

In this study, $316 L$ with particles' size between 45 and $75 \mu \mathrm{m}$ is used to fabricate the experimental single laser tracks on steel substrates (Fig. 4). For each single laser track power, powder feed rate and velocity are kept constant. The process duration is adjusted in order to obtain always the same length track of $9 \mathrm{~cm}$. Each single laser track is produced on the same steel plate with the same dimensions shown in Fig. 5a. To avoid any board effect, the 6 laser tracks are carried out at a distance of $10 \mathrm{~mm}$ from the substrate boards as shown in Fig. 5b-c.

Experimental results are evaluated by observations on the laser tracks' cross sections. Cross section characteristics change with power, velocity and feed mass rate. Characteristics of each single track are evaluated by measures of the clad height $(H)$, clad width $(W)$ and the depth penetration $\left(H_{f}\right)$, area $(S)$ and area of penetration $\left(S_{f}\right)$ (Fig. 6).

To study the effects of the main laser cladding parameters on the clad geometry, tracks were produced in a wide variety of power $P(180,280$ and $360 \mathrm{~W})$, velocity $V(300,600$ and $900 \mathrm{~mm} /$ min) and mass feed rate $Q_{m}(0.025,0.05$ and $0.075 \mathrm{~g} / \mathrm{s})$. Samples are polished and etched with Nital (2\%). Every combination of the 3 values of the 3 parameters is explored, which represents 27 single tracks. For each one 2 cross-sections are studied and the mean result is reported in Table 1.

\section{Results and discussion}

For each cross section a measure of the mean micro-hardness is realized. For all the 27 laser tracks the result is between 160 and $210 \mathrm{HV}$ (Table 2). The determination of the chemical

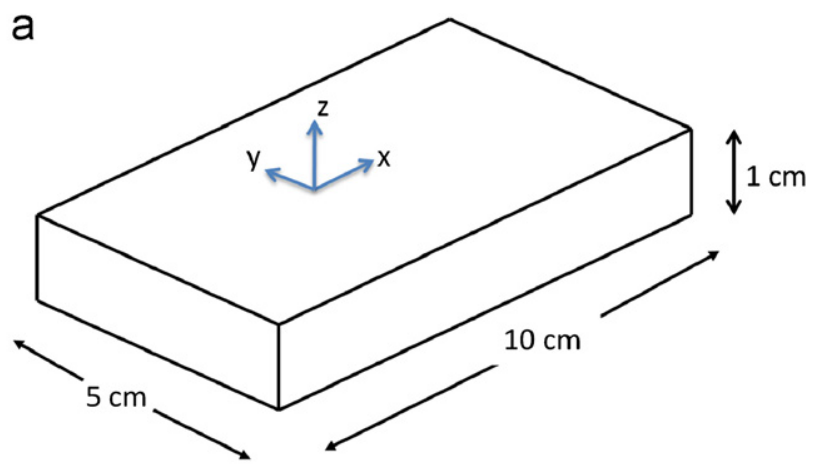

b
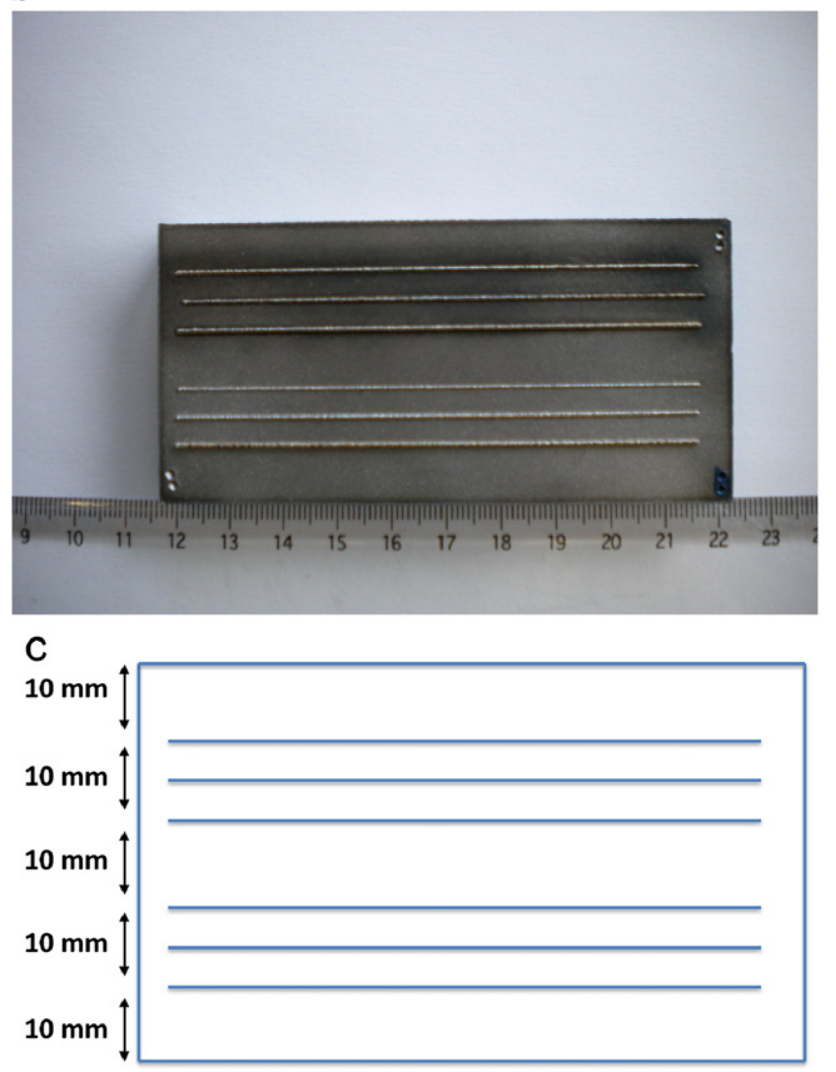

Fig. 5. (a) Substrate dimensions. (b) Image showing single tracks on a steel substrate. c) Single track deposition on the substrate.

composition shows that $316 \mathrm{~L}$ is melted with more or less substrate steel. In the Melted Zone the chemical composition is uniform due to the Marangoni effect. An abrupt variation is 


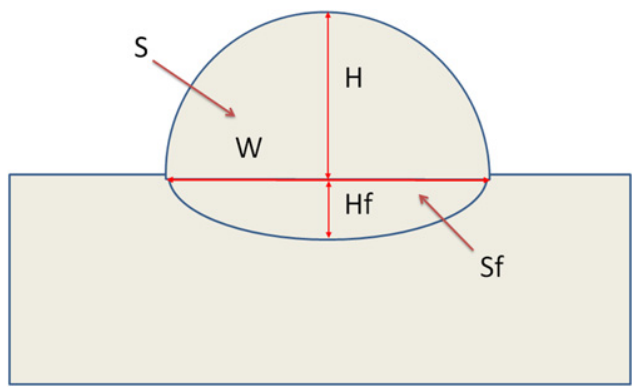

Fig. 6. Cross section measures for each single track.

Table 1

Parameters and experimental measures for each single track.

\begin{tabular}{|c|c|c|c|c|c|c|c|c|}
\hline Depots & $\begin{array}{l}P \\
(\mathbf{W})\end{array}$ & $\begin{array}{l}Q_{m} \\
(\mathrm{~g} / \mathrm{s})\end{array}$ & $\begin{array}{l}V(\mathrm{~mm} / \\
\mathrm{min})\end{array}$ & $\begin{array}{l}W \\
(\mathbf{m m})\end{array}$ & $\begin{array}{l}\boldsymbol{H} \\
(\mathbf{m m})\end{array}$ & $\begin{array}{l}S \\
\left(\mathrm{~mm}^{2}\right)\end{array}$ & $\begin{array}{l}\boldsymbol{H}_{\boldsymbol{f}} \\
(\mathbf{m m})\end{array}$ & $\begin{array}{l}S_{f} \\
\left(\mathrm{~mm}^{2}\right)\end{array}$ \\
\hline 1 & 180 & 0,025 & 300 & 0.56 & 0.47 & 0.25 & 0.03 & 0.01 \\
\hline 2 & 180 & 0,025 & 600 & 0.50 & 0.19 & 0.07 & 0.05 & 0.01 \\
\hline 3 & 180 & 0,025 & 900 & 0.43 & 0.15 & 0.05 & 0.05 & 0.08 \\
\hline 4 & 180 & 0,050 & 300 & 0.41 & 0.73 & 0.53 & 0.00 & 0.00 \\
\hline 5 & 180 & 0,050 & 600 & 0.38 & 0.39 & 0.19 & 0.00 & 0.00 \\
\hline 6 & 180 & 0,050 & 900 & 0.42 & 0.24 & 0.09 & 0.02 & 0.00 \\
\hline 7 & 180 & 0,075 & 300 & 0.28 & 0.81 & 0.59 & 0.00 & 0.00 \\
\hline 8 & 180 & 0,075 & 600 & 0.39 & 0.47 & 0.22 & 0.00 & 0.00 \\
\hline 9 & 180 & 0,075 & 900 & 0.40 & 0.33 & 0.12 & 0.00 & 0.00 \\
\hline 10 & 360 & 0,025 & 300 & 0.83 & 0.49 & 0.36 & 0.22 & 0.11 \\
\hline 11 & 360 & 0,025 & 600 & 0.72 & 0.27 & 0.15 & 0.15 & 0.07 \\
\hline 12 & 360 & 0,025 & 900 & 0.68 & 0.20 & 0.09 & 0.15 & 0.07 \\
\hline 13 & 360 & 0,050 & 300 & 0.86 & 0.82 & 0.76 & 0.13 & 0.06 \\
\hline 14 & 360 & 0,050 & 600 & 0.71 & 0.42 & 0.27 & 0.21 & 0.09 \\
\hline 15 & 360 & 0,050 & 900 & 0.62 & 0.26 & 0.14 & 0.22 & 0.08 \\
\hline 16 & 360 & 0,075 & 300 & 0.90 & 0.90 & 0.89 & 0.07 & 0.03 \\
\hline 17 & 360 & 0,075 & 600 & 0.73 & 0.59 & 0.41 & 0.14 & 0.06 \\
\hline 18 & 360 & 0,075 & 900 & 0.71 & 0.35 & 0.18 & 0.17 & 0.07 \\
\hline 19 & 280 & 0,025 & 300 & 0.66 & 0.32 & 0.17 & 0.15 & 0.07 \\
\hline 20 & 280 & 0,025 & 600 & 0.60 & 0.14 & 0.06 & 0.07 & 0.04 \\
\hline 21 & 280 & 0,025 & 900 & 0.53 & 0.09 & 0.03 & 0.07 & 0.03 \\
\hline 22 & 280 & 0,050 & 300 & 0.64 & 0.68 & 0.52 & 0.06 & 0.03 \\
\hline 23 & 280 & 0,050 & 600 & 0.62 & 0.37 & 0.19 & 0.15 & 0.05 \\
\hline 24 & 280 & 0,050 & 900 & 0.55 & 0.22 & 0.09 & 0.11 & 0.04 \\
\hline 25 & 280 & 0,075 & 300 & 0.65 & 0.80 & 0.70 & 0.03 & 0.01 \\
\hline 26 & 280 & 0,075 & 600 & 0.56 & 0.47 & 0.28 & 0.12 & 0.04 \\
\hline 27 & 280 & 0,075 & 900 & 0.56 & 0.27 & 0.12 & 0.13 & 0.04 \\
\hline
\end{tabular}

observed at the interface between the Melted Zone and the Affected Zone.

Fig. 7 shows the laser tracks' cross sections. $P$ remaining constant, the laser track height $(H)$ and the cross section area $(S)$ decrease if the velocity increases and increase if the powder feed rate increases. For low velocities and high feed rate powder, the powder accumulation leads to the formation of cylindrical laser tracks. On the other hand for high velocities and low feed rate powder the clad profile is flattened. Powder feed rate and velocity remain constant, the more the power $P$ increases the more the track area increases and so the more the mass of incorporated powder per meter $(\mathrm{g} / \mathrm{m})$ increases.

\subsection{Parametric study}

The clad geometry and the mass deposit of each single track change with the parameters $\left(P, Q_{m}, V\right)$. The power or the feed rate increase or the velocity decrease leads to an increase of the clad mass. The clad mass is measured after each single track fabrication for two Power series (180 and 360); due to a technical problem we have not been able to measure the mass clad for the $280 \mathrm{~W}$ series.
Table 2

Hardness and chemical composition of 316L

\begin{tabular}{lll}
\hline Particle size & Hardness & Chemical composition (maximum value) \\
\hline $\mathbf{4 5 - 7 5} \boldsymbol{\mu m}$ & $160-210 \mathrm{HV}$ & $\begin{array}{l}0.03 \% \mathrm{C}, 2 \% \mathrm{Mg}, 1 \% \mathrm{Si}, 0.03 \% \mathrm{~S}, \\
0.045 \% \mathrm{P}, 10-14 \% \mathrm{Ni}, 2-3 \% \mathrm{Mo}, 16-18 \% \mathrm{Cr}\end{array}$ \\
& &
\end{tabular}

Puissance $=180 \mathrm{~W}$

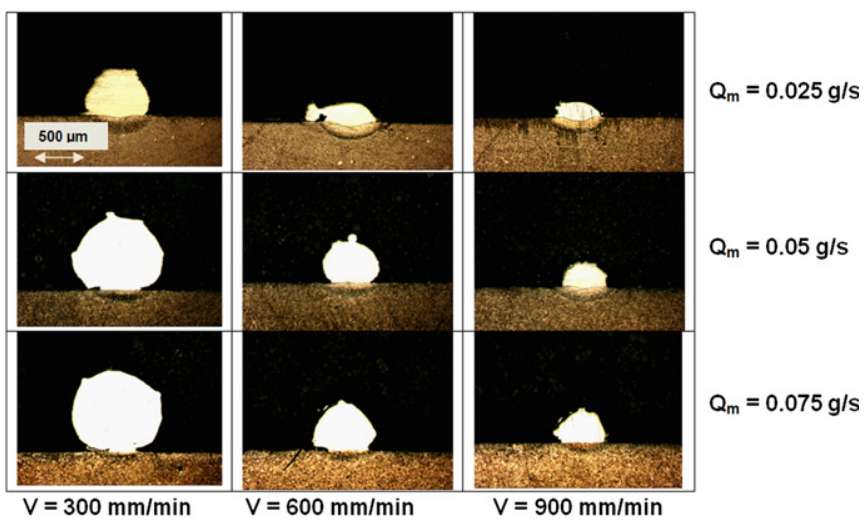

Puissance $240 \mathrm{~W}$
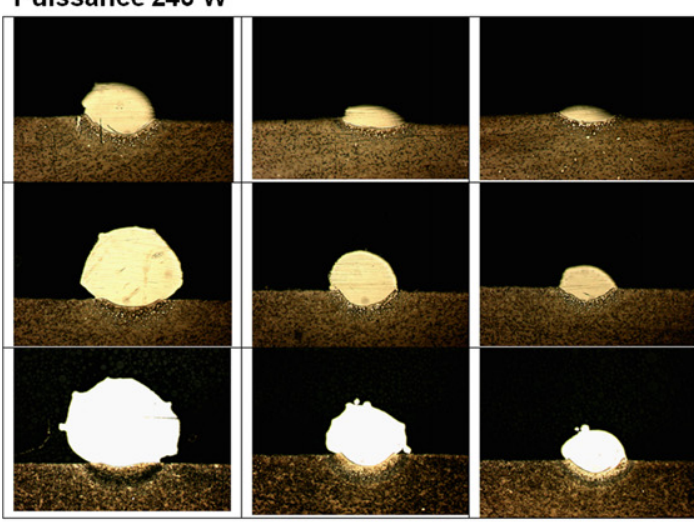

$Q m=0.025 \mathrm{~g} / \mathrm{s}$

$V=300 \mathrm{~mm} / \mathrm{min}$

$\mathrm{V}=600 \mathrm{~mm} / \mathrm{min}$

$V=900 \mathrm{~mm} / \mathrm{min}$

\section{Puissance $360 \mathrm{~W}$}
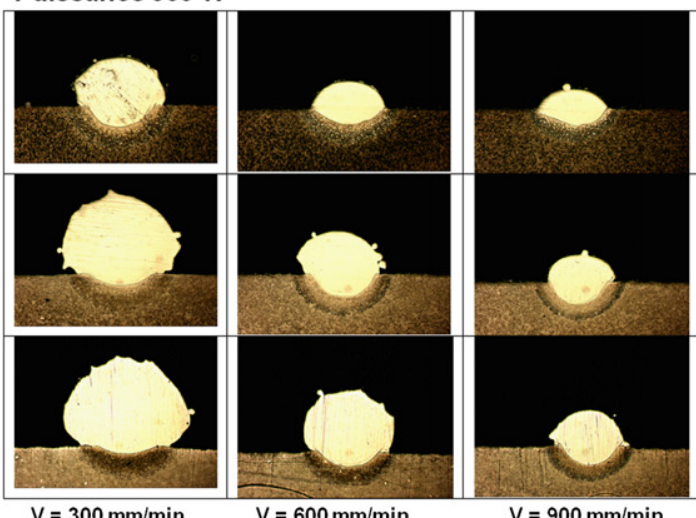

$Q m=0.025 \mathrm{~g} / \mathrm{s}$

Fig. 7. All single tracks' cross-section. For each laser power the velocity $(V)$ increases from the left to the right and the feed rate $\left(Q_{m}\right)$ increases from the top to the bottom.

Being capable to predict the laser track characteristics is important as a first step to build a wall and finally to fabricate an object. C. Oliveira [36] studied the regression analysis as $Y=\alpha_{0}+\alpha x_{1}+\alpha_{2} x_{2}+\ldots+\alpha_{n} x_{n}$ where $x_{i}$ are the process parameters. Nevertheless correlation coefficients presented are quite 
low. In [34], De Oliveira searched more persuasive relations like $P^{\alpha} Q_{m}{ }^{\beta} V^{\gamma}$. In our study, we also made the assumption that some combinations as $\left(P^{\alpha} Q_{m}^{\beta} V^{\gamma}\right)$ are able to predict the different laser track geometry characteristics. Using the Log function a linear regression is used to determine $\alpha, \beta$ and $\gamma$. We finally obtain a relationship as $y=a\left(P^{\alpha} Q_{m}{ }^{\beta} V^{\gamma}\right)+b$ where $y$ is one of the laser track geometry parameters while a and $b$ are constants. With our experimental results, we find that $H$ is proportional to $P^{(1 / 4)} Q_{m}{ }^{(3 / 4)} V^{-1}$ with a correlation coefficient $R=0.97$ (i.e. $R^{2}=0.94$ ) taking into account all the 27 experiments. Fig. 8 shows these results.

The powder mass, which falls on the substrate per meter, is $Q_{m}$ $V^{-1}$ (this is also the relationship proposed by De Oliveira [34]). Nevertheless the laser power plays a non-negligible part because it melts the powder grains and the more the amount of powder melts the more the clad height increases. The correct representation of the relation between clad height and the process parameters could be written in the form $P^{(1 / 4)} Q_{m}{ }^{(3 / 4)} V^{-1}=\left(P / Q_{m}\right)^{(1 / 4)}\left(Q_{m} / V\right)$. The $R$ coefficient value of 0.97 shows a good correlation and the uniform distribution of the residuals confirms the linear model. The experimental repeatability uncertainty for the clad height is $0.040 \mathrm{~mm}$. If we use the linear regression formulae to predict the clad height from the process parameters the uncertainty on this calculated clad height is $0.060 \mathrm{~mm}$. These two values are sufficiently narrow to show that this linear relationship between $H$ and $P^{(1 / 4)} Q_{m}{ }^{(3 / 4)} V^{-1}$ is relevant.

The width of the clad is also proportional to a similar process parameters' combination, with $\alpha=0.75, \beta=0$ and $\gamma=-0.25$ (Fig. 9). It is to be noticed that the mass feed rate $Q_{m}$ has a negligible influence on the clad width. This is in agreement with the work of De Oliveira [34], who found the width proportional to be $P V^{-(1 / 2)}$. The two parameters laser power and velocity are sufficient to determine the width of the single track, which could be the sign of a thermal effect like in the re-melted process. With our experimental measures we find a correlation coefficient $\mathrm{R}=0.96$ with $P^{(3 / 4)} V^{-(1 / 4)}$. The experimental repeatability uncertainty concerning the width is $0.040 \mathrm{~mm}$, whereas the uncertainty on the estimated width using the linear dependence between $W$ and $P^{(3 / 4)} V^{-(1 / 4)}$ is $0.068 \mathrm{~mm}$, which is comparable with the previous height uncertainty.
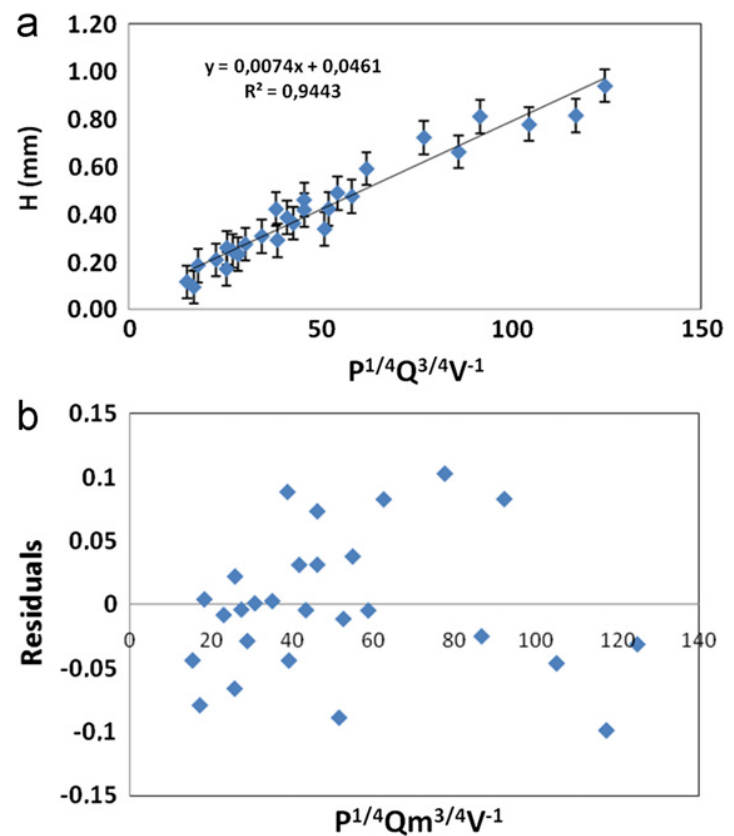

Fig. 8. (a) Laser track height $H$ versus $P^{1 / 4} Q_{m}^{3 / 4} / V^{-1}$. (b) Residuals.
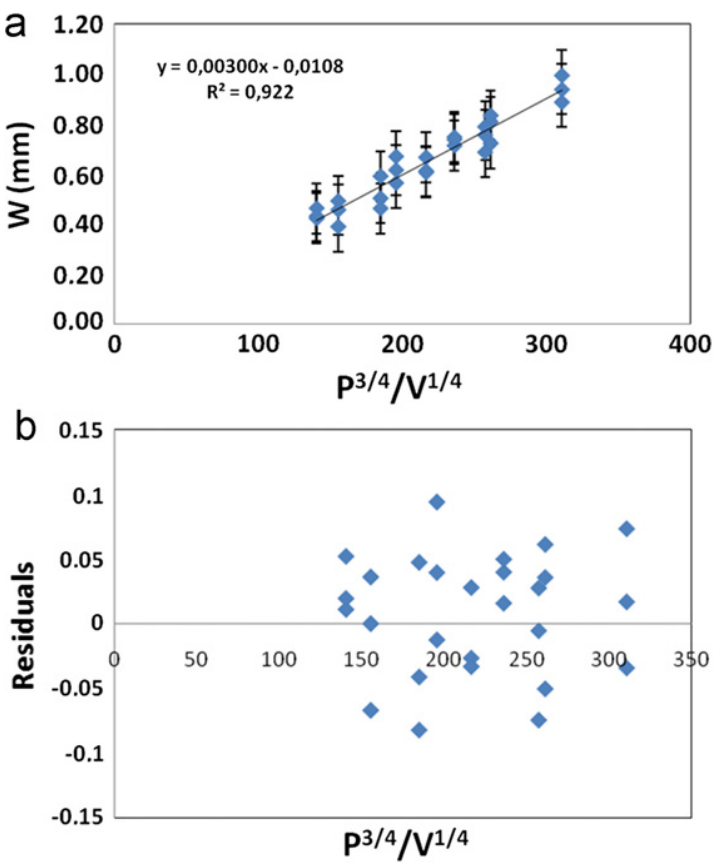

Fig. 9. (a) Clad width versus $P^{3 / 4} / V^{1 / 4}$. (b) Residuals.

Concerning the clad section area, the same method leads to $P Q_{m} V^{-(3 / 2)}$ with a coefficient $R$ of 0.978 . The repeatability uncertainty is $0.025 \mathrm{~mm}^{2}$ and the uncertainty obtained for the estimated surface with the linear relationship is $0.049 \mathrm{~mm}^{2}$ (Fig. 10).

Of course the clad mass is also proportional to $P Q_{m} V^{-(3 / 2)}$ as the clad mass is proportional to the cross section surface (Fig. 11).

We have also determined the relationship between the experimental parameters and the useful powder measuring the powder mass, which stays on the substrate [Table 3]. The uncertainty is $4.1 \%$ for the repeatability uncertainty and $5.2 \%$ for the estimated one. This is an important criterion because one of the Direct Laser Process goals is to not lose matter by machining.

These relationships are very useful to predict the clad width and height, but not the complete geometry, and it does not help to understand the physical phenomenon involved during the process. Another way to predict the clad geometry is to simulate the supposed physical phenomenon involved.

\subsection{Study of the powder distribution}

The deposited layer results from the powder accumulation and so the clad height could be supposed to be proportional to the powder grains, which fall on each point. Three powder distributions in the jet are tried [41]. In this case the clad geometry is directly induced by the powder distribution in the jet.

All Eqs. (7), (8), (10)-(12) are obtained by the same method (Fig. 12).

The powder distribution is given by $f(x, y)$ and expressed in units: $\mathrm{kgm}^{-2} \mathrm{~s}^{-1}$. The mass, which fell on a little surface $(\mathrm{ds}=\mathrm{d} x \mathrm{~d} y)$ after the passage of the laser, is given by

$d m=\int_{0}^{t} f(x, y) d x d y d t$

The time $t$ during which the powder fall on this surface is given by

$t=\frac{b}{V}$ 

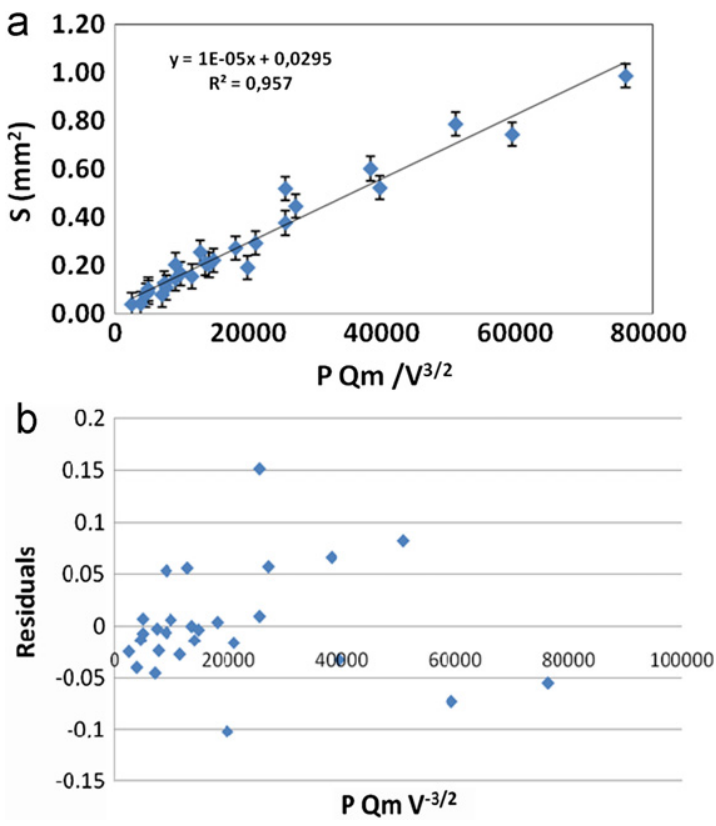

Fig. 10. (a) Clad area versus $P Q_{m} / V^{3 / 2}$. (b) Residuals.

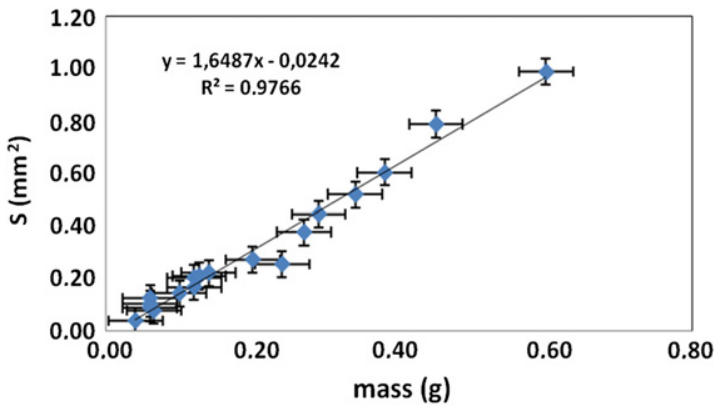

Fig. 11. Linear dependence between the surface of cross section and the clad mass at $P=180 \mathrm{~W}$ and $P=360 \mathrm{~W}$.

Table 3

Relationships between the geometrical characteristics of the cross sections and the process parameters, where Pe is the powder efficiency.

\begin{tabular}{lll}
\hline Grandeur & Combinaison des paramètres & Coefficient de correlation $\left(\boldsymbol{R}^{2}\right)$ \\
\hline$H$ & $P^{(1 / 4)} Q m^{(3 / 4)} / V$ & 0.944 \\
$W$ & $P^{(3 / 4)} V^{(1 / 4)}$ & 0.922 \\
$S$ & $P Q m / V \sqrt{V}$ & 0.957 \\
$m$ & $P Q m / V \sqrt{V}$ & 0.934 \\
$P_{e}$ & $P^{(3 / 4)} Q_{m}^{(-1 / 3)} V^{(-1 / 2}$ & 0.910 \\
$S_{f}$ & $\operatorname{Ln}\left(P^{(4 / 5)} Q_{m}^{(-1 / 4)}\right)$ & 0.649 \\
$H_{f}$ & $\operatorname{Ln}\left(P^{2} V^{(1 / 4)} Q_{m}^{(-1 / 4)}\right)$ & 0.765 \\
\hline
\end{tabular}

where $b$ is the chord of the powder deposition disk:

$t=\frac{2 r_{p}}{V} \sqrt{1-\frac{y^{2}}{r_{p}^{2}}}$

The height of powder $h$, which fell under the studied surface behind the powder jet, is given by

$\rho=\frac{d m}{h d x d y} \rightarrow h=\frac{d m}{\rho d x d y}$

where $\rho$ is the powder density.
And finally

$h=\frac{1}{\rho} \int_{0}^{\left(2 \mathrm{r}_{\mathrm{p}} / V\right) \sqrt{1-\left(\mathrm{y}^{2} / \mathrm{r}_{\mathrm{p}}^{2}\right)}} f(x, y) d t$

Beneath the powder jet, $b$ is only a part of the chord and so depends on $x$ and $y$.

$h=\frac{1}{\rho} \int_{0}^{(\mathrm{b}(x, y) / V)} f(x, y) d t$

\subsubsection{Uniform distribution}

If the powder distribution is uniform, the density of the powder feed rate is given by $f(x, y)=\left(Q_{m} / \pi r_{p}^{2}\right)$ where $Q_{m}$ is the powder feed rate and $r_{p}$ the radius of the powder deposition circle.

One can find that behind the powder jet the profile is given by

$\frac{2 Q_{m}}{\rho \pi v r_{p}^{2}} \sqrt{r_{p}^{2}-y^{2}}$

and beneath the powder jet by (Fig. 13)

$\frac{2 Q_{m}}{\rho \pi v r_{p}^{2}} \sqrt{r_{p}^{2}-y^{2}}-(x-v t)$

\subsubsection{Gaussian distribution}

If the powder distribution is Gaussian along the $x$ and the $y$ axes:

$f(x, y)=\frac{Q_{m}}{\pi r_{p}^{2}} e^{-\left((x-V t)^{2}+y^{2} / r_{p}^{2}\right)}$

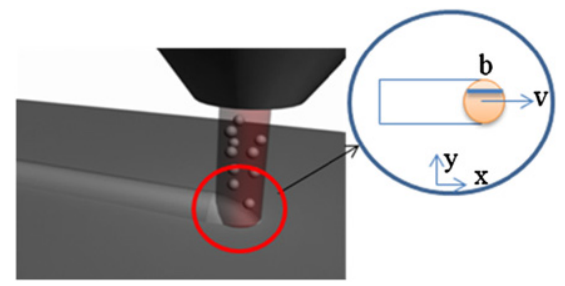

Fig. 12. Powder deposition on the substrate surface.
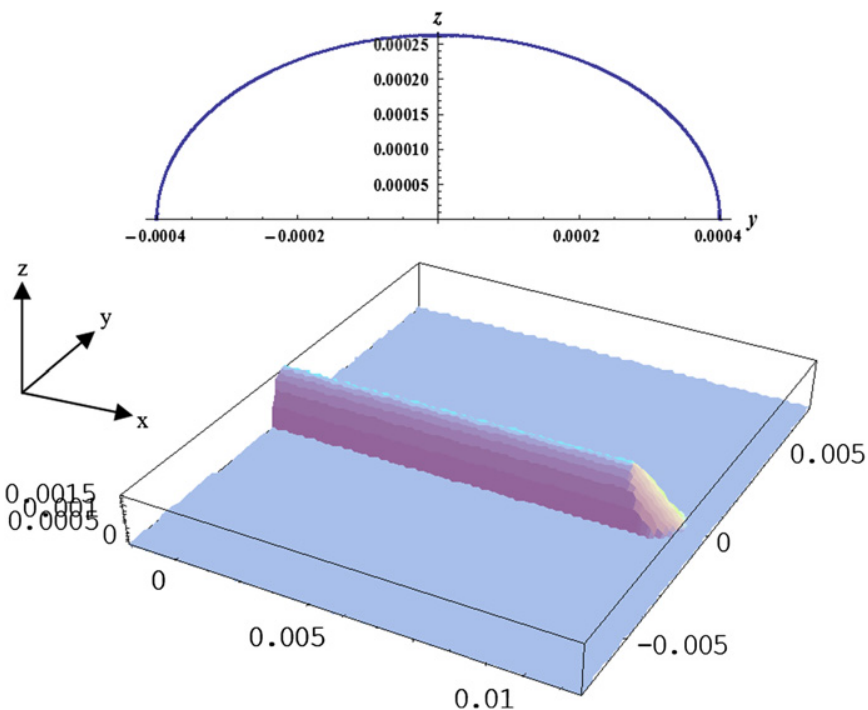

Fig. 13. Geometry of the deposited layer in case of a uniform powder distribution. 
one can find that the profile behind and beneath the powder jet takes the following form (Fig. 14):

$\frac{2 Q_{m}}{2 \sqrt{\pi} v \rho r_{p}^{2}} e^{\left(-y^{2} / r_{p}^{2}\right)}\left[\operatorname{erf}\left(\frac{x}{r_{p}}\right)-\operatorname{erf}\left(\frac{x-v t}{r_{p}}\right)\right]$
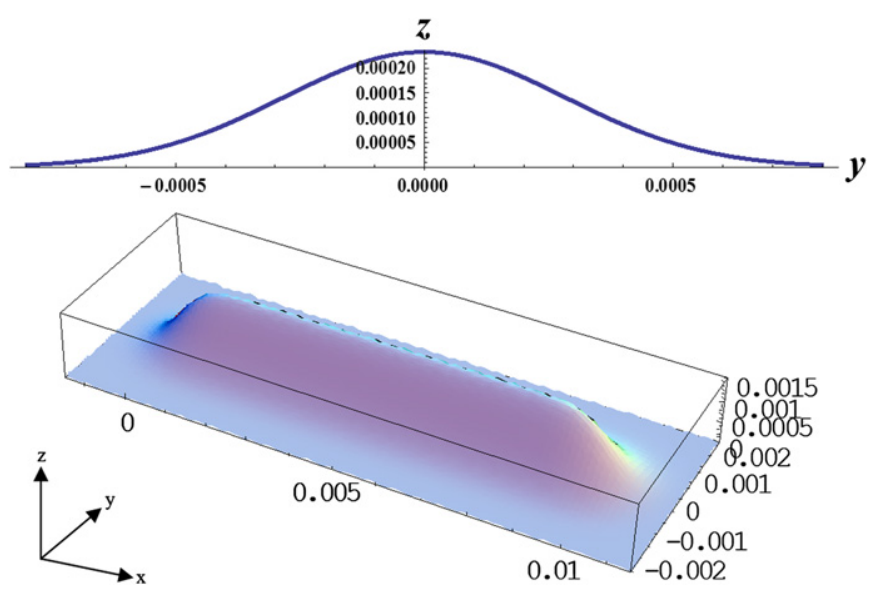

Fig. 14. Geometry of the deposited layer in case of a Gaussian powder distribution.

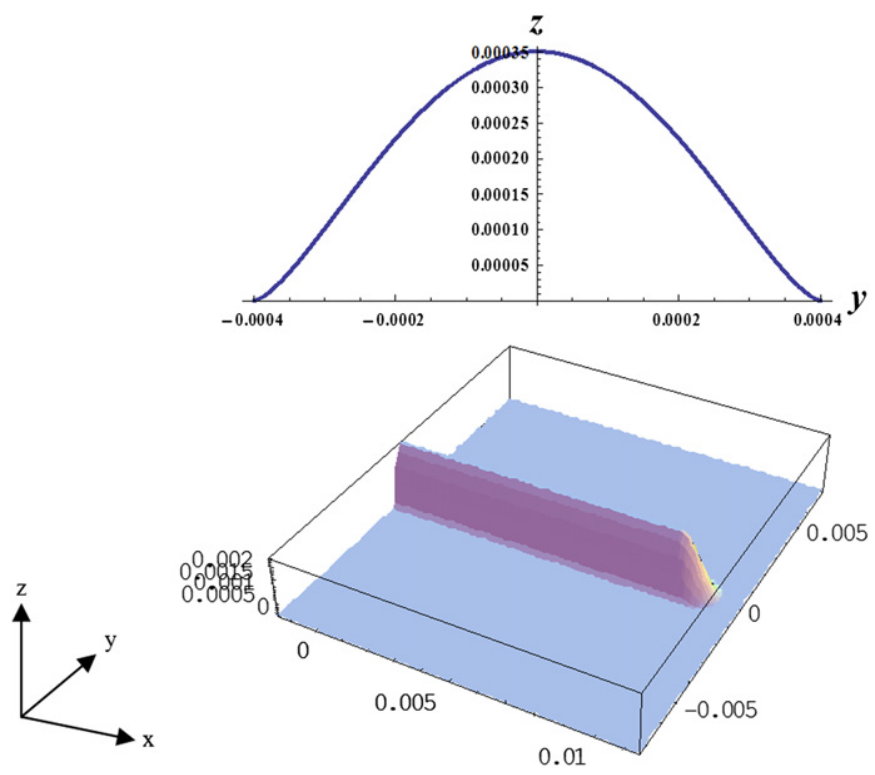

Fig. 15. Geometry of the deposited layer in case of a polynomial distribution.

\subsubsection{Polynomial distribution}

In a third time we consider that the distribution is a parabolic one given by $f(x, y)=a r^{2}+b r+c=a(x+y)^{2}+b(x+y)+c$

One can find that under the powder jet:

$\frac{8 Q_{m}}{3 \pi v \rho \cdot r_{p}{ }^{4}}\left(r_{p}^{2}-y^{2}\right)^{(3 / 2)}$

The equation behind the powder jet is

$\frac{2 Q_{m}\left[(x-v t)^{3}+3(x-v t) y^{2}-2 y^{2} \sqrt{r_{p}^{2}-y^{2}}+r_{p}^{2}\left(-3(x-v t)+2 \sqrt{r_{p}^{2}-y^{2}}\right)\right]}{\rho \pi v r_{p}^{2}}$

and zero everywhere else [Fig. 15].

We can notice that with this approach the laser power is not taken into account. Concerning the height $H$, this is not really significant because $H$ has been found experimentally proportional to $P^{(1 / 4)} Q_{m}{ }^{(3 / 4)} V^{-1}$ and so in our case $\mathrm{P}^{1 / 4}$ varies from 1 to 1.19 while $\mathrm{Qm}^{3 / 4}$ varies from 1 to 2.28 and $\mathrm{V}^{-1}$ from 1 to 3 . On the other hand it is critical for the determination of $W$, which has been found proportional to $P^{(3 / 4)} V^{-(1 / 4)}$. This can be explained by the fact that the width of the clad is controlled by a thermal effect, which depends directly on the power $P$. This parameter plays an important part on the powder melting in the jet and on the melting bath dimensions.

Fig. 16 shows fittings on two different laser tracks geometries, representative of a spread one and a near semi-circular one. While the experimental cross section is represented by the blue points, the blue curve corresponds to the uniform distribution, the red one to the polynomial distribution and the green one to the Gaussian distribution.

For low single laser tracks' heights, the Gaussian distribution leads to a function, which goes through the most part of the experimental points but that is not able to well represent sides of the laser tracks. This distribution is also the most likely one at the sight of the powder stream analysis in Fig. 2.

The uniform distribution can well describe the laser track geometry when the height is nearly equal to the half of the width, which corresponds to a semi-circular laser clad (Fig. 17).

One can use the proposed analytical relationships for specific conditions but it is not likely that the powder distribution in the jet changes from a Gaussian distribution to a uniform one with the process parameters. Furthermore in the case of the lower laser speeds the clad geometry is a part of a disk and none of these distributions can lead to such geometry. We conclude that in our case the laser clad geometry is not directly induced by the powder distribution in the jet. In order to simulate the laser clad
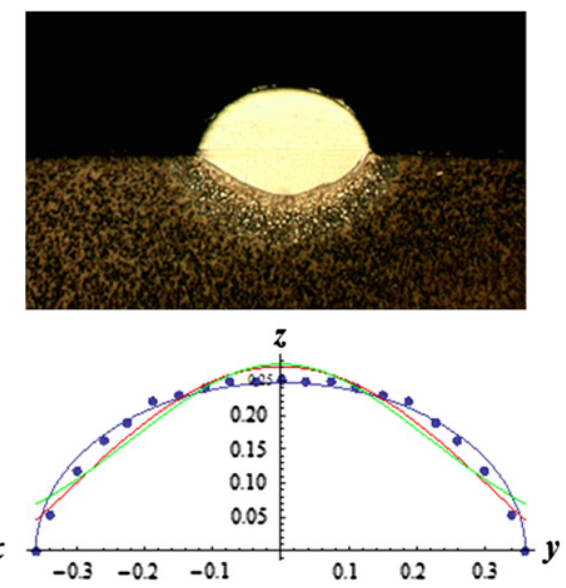

Fig. 16. Fitting with the three different functions to describe our experimental results. 

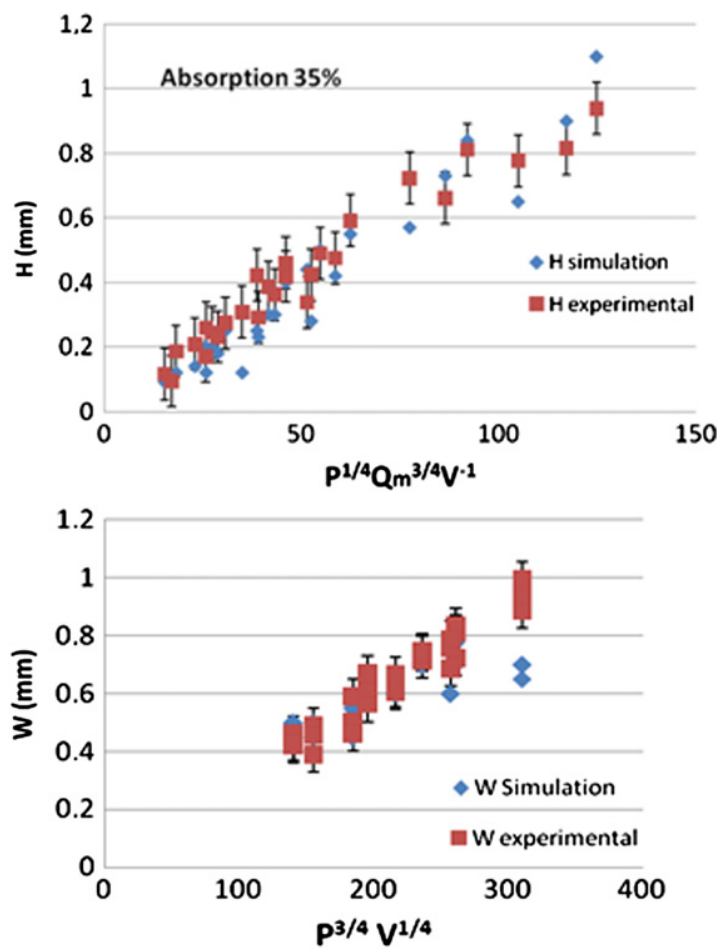

Fig. 17. Confrontation of the experimental height and width with the simulated results in the case of a Gaussian distribution.

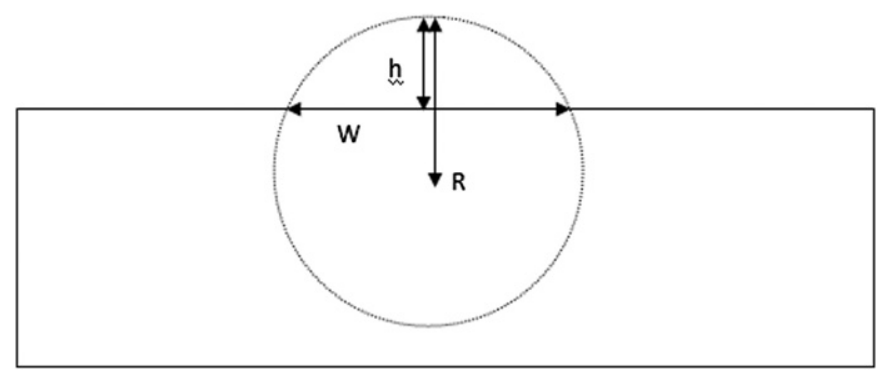

Fig. 18. Schematic view of the circular form model. The width $W$ of the clad is the chord of the circle of radius $R$. $h$ is the height of the deposit clad. process in the stationary case, it is more efficient to fix the crosssection geometry as a part of a disk.

\subsection{Circular form}

Let us take notice that the geometry is always a part of a disk, in which the center can be below or above the workpiece surface. Such geometry can be explained by the surface tension effect [42]. The disk center goes above the workpiece surface when the velocity is not great enough to avoid the accumulation of the deposited material. The utility of this model is to predict the height, the width, the surface and the general form of the cross section in any case.

The analytical relationships presented in the first part of this article are used to calculate the geometrical characteristics of the simulated clad. The width $W=0.003 P^{(3 / 4)} V^{(-1 / 4)}-0.0108$ is equal to the disk chord at $z=0$. The powder efficiency $P_{e}=0.312 \operatorname{Ln}\left(P^{3 / 4} / V^{1 / 2} Q_{m}{ }^{1 / 3}\right)-1.995$ is used to calculate the surface of the clad section $\left(P_{e} Q_{m} / \rho V\right)$. Our problem is now a geometrical one: Knowing the chord length and the upper surface section, where is the circle center and what is the radius value?

Harris and Stocker [43] have shown that the area of the disk segment above the chord (Fig. 18) can be expressed as

$A=\frac{2}{3} W h+\frac{h^{3}}{2 W}$

accurate to within $0.8 \%$ in any case.

This expression is equivalent to

$A=\frac{h}{6 W}\left(4 W^{2}+3 h^{2}\right)$

A geometrical analysis can lead to express $h$ as a function of the variables $R$ and $W$ :

$h=R\left(1-\sqrt{1-\left(\frac{W}{2 R}\right)^{2}}\right)$

Replacing $h$ by this formula, one can find that

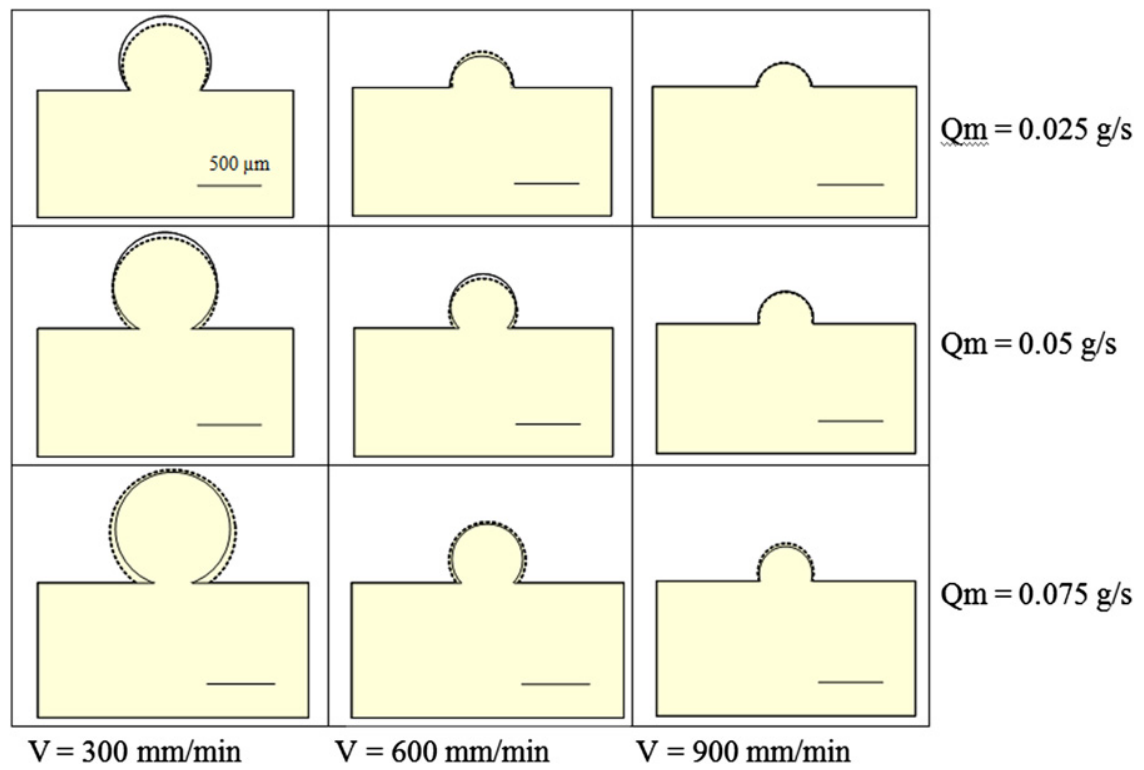

Fig. 19. Confrontation of the experimental results (continuous line) and the simulation results (obtained with the linear relationships, dash line) at $P=180 \mathrm{~W}$. 
If $\left(P_{e} Q_{m} / \rho V\right)<\left(\pi W^{2} / 8\right)$ the radius $R$ is obtained solving the equation:

$\frac{P_{e} Q_{m}}{\rho V}=\frac{1}{6 W}\left(R\left(1-\sqrt{1-\left(\frac{W}{2 R}\right)^{2}}\right)\left(3 R^{2}\left(1-\sqrt{1-\left(\frac{W}{2 R}\right)^{2}}\right)^{2}+4 W^{2}\right)\right.$

The center is below the substrate surface and at a distance

$\sqrt{R^{2}-\left(\frac{W}{2}\right)^{2}}$

from it.

If $\left(P_{e} Q_{m} / \rho V\right)>\left(\pi W^{2} / 8\right)$, the radius is calculated from the following equation:

$\frac{P_{e} Q_{m}}{\rho V}=\pi R^{2}-\frac{1}{6 W}\left(R\left(1-\sqrt{1-\left(\frac{W}{2 R}\right)^{2}}\right)\right)\left(3 R^{2}\left(1-\sqrt{1-\left(\frac{W}{2 R}\right)^{2}}\right)^{2}+4 W^{2}\right)$

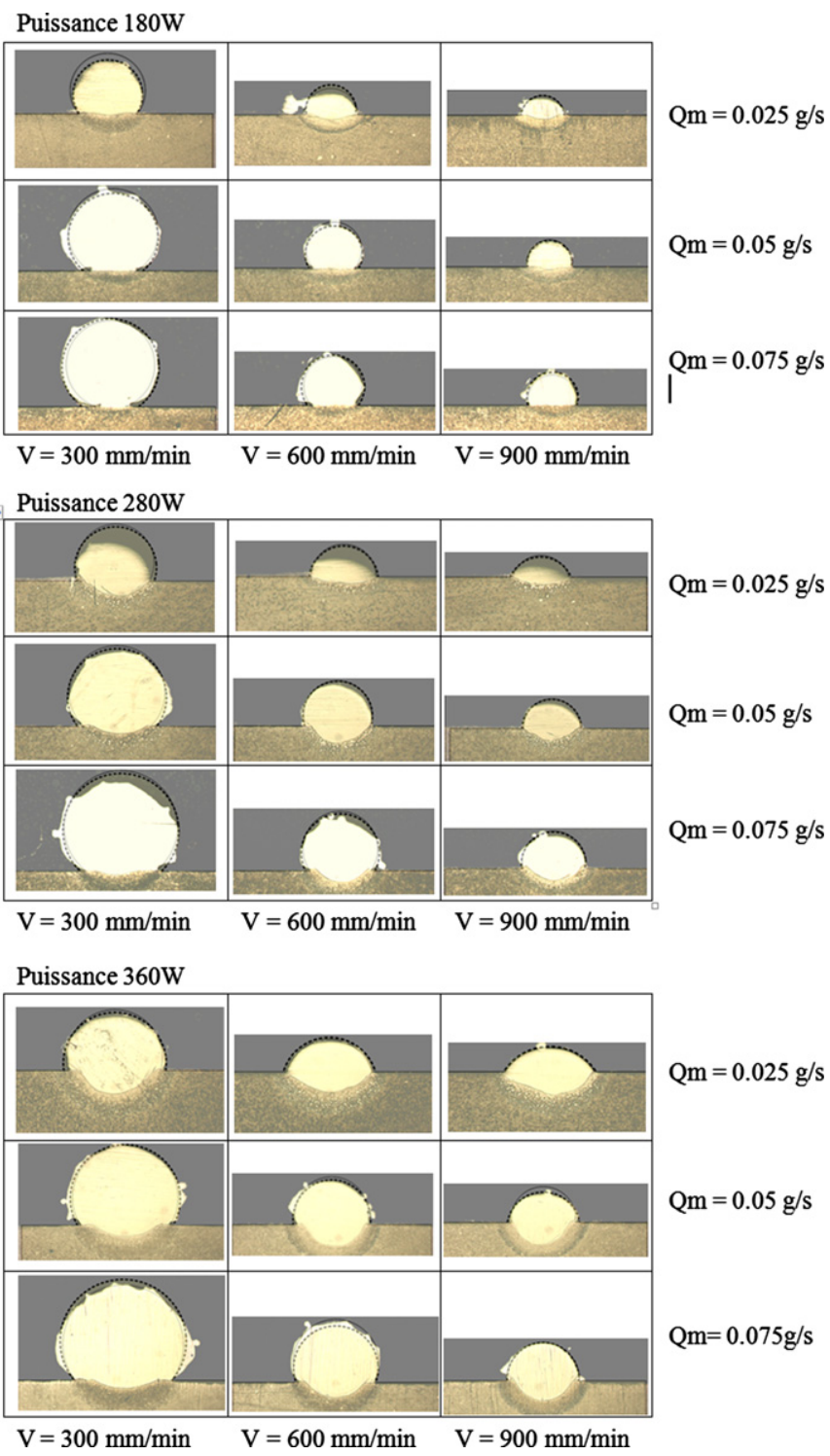

Fig. 20. Superposition of the micrographic observations, the experimental results (continuous line) and the simulated results (obtained with the linear relationships, dash line).
The center is above the surface substrate and at a distance

$\sqrt{R^{2}-\left(\frac{W}{2}\right)^{2}}$

from it.

In Fig. 19, simulated profiles are obtained with the analytical relationships presented in the first part of this work. Experimental results are obtained using the true measures of width and height. The use of the linear relationships leads to representations of the clad cross sections very narrow from the experimental ones.

Assuming the fact that the geometry of the clad cross-section is always a part of a disk, Fig. 20 shows superimpositions of our predictions and pictures of our experimental results. A significant difference is observed only in the case of the laser power $280 \mathrm{~W}$ and the lowest mass feed rate $0.025 \mathrm{~g} / \mathrm{s}$. So we are able to simulate the laser clad process from the analytical relationships presented in the first part of this article and the assumption of a disk form is confirmed.

\section{Conclusion}

Relationships such as $\left(P^{\alpha} Q_{m}^{\beta} V^{\gamma}\right)$ between process parameters and cross sectional characteristics (height, width, area, etc.) have been established using the multiple regression analysis method. The good correlation coefficients obtained and the associated residuals analysis confirm the pertinence of such an approach for our experimental results. The track's height is found proportional to $\left(P / Q_{m}\right)^{(1 / 4)}\left(Q_{m} / V\right)$. The first part of this formula represents the intake of energy per unit of mass and so the quantity of melted powder while the second part $Q_{m} / V$ represents the mass of powder per unit of length. The clad width is also found to be proportional to a similar combination of the process parameters: $P^{(3 / 4)} V^{-(1 / 4)}$. This result is very similar to the one found by de Oliveira [9]: $P V^{-(1 / 2)}$. The fact that only the power $P$ and the velocity $V$ appear in this formula shows that thermal effects govern the clad width determination like in the laser re-melting process. The relationship between the experimental parameters and the useful powder has also been determined. These formulae permit the determination of some geometrical characteristics of the clad. But this is not a full description of the clad geometry. We first propose a determination of the clad geometry from the powder distribution in the jet. Three analytical functions are established for the three distributions studied. Each of them is able to treat some of our results but none of them is able to treat all our results. So we conclude that in our case the powder distribution in the jet is not determining for the final clad geometry (even so the coaxial nozzle must ensure the powder melting in the laser beam and the continuity of the melted metal on the substrate surface). Assuming the fact that the clad geometry is governed by the surface tension on the melted bath and that the clad geometry is a part of a disk it is shown that it is possible to predict, with a good uncertainty, the complete geometrical characteristics of laser clad.

\section{Acknowledgments}

Thanks to Gilles Carrabin for his mastery of the machine. Thanks to the "region des pays de la Loire" for its financial support within the PREMS project.

\section{References}

[1] Hu YP, Chen CW, Mukherjee K. Development of a new laser cladding process for manufacturing cutting and stamping dies. J. Mater. Sci. 1998;33:1287-92. 
[2] Steen WM. Laser material processing. Berlin: Springer; 1991.

[3] Courant BB, Hantzpergue JJ, Benayoun S. Surface Treatment of titanium by laser irradiation to improve resistance to dry-sliding friction. Wear 1999; 236(1-2):39-46.

[4] Courant B, Hantzpergue JJ, Avril L, Benayoun S. Structure and hardness of titanium surfaces carburized by pulsed laser melting with graphite addition. J. Mater. Process. Technol. 2005;160:374-81.

[5] Kerbrat O, Mognol P, Hascoët J-Y. Manufacturability analysis to combine additive and subtractive processes. Rapid Prototyp. J 2010;16(1):63-72.

[6] Pessard E, Mognol P, Hascoët JY, Gerometta C. Complex cast parts with rapid tooling: Rapid manufacturing point of view. Int J. Adv. Manuf. Technol. 2008;39:898-904.

[7] Lalas C, Tsirbas K, Salonitis K, Chryssolouris G. An analytical model of laser clad geometry. Int J. Adv. Manuf. Technol. 2007;32:34-41.

[8] Mazumder J, Dutta D, Kikuchi N, Ghosh A. Closed loop direct metal deposition: art to part, Opt. Lasers Eng 2000;34:397-414.

[9] Courant B, Hantzpergue JJ, Benayoun S, L'huillier JP. Melting and solidification processes in a moving graphite-covered titanium surface subjected to multipulsed laser irradiation. J. Phys. D : Appl. Phys 2001;34:1437-46.

[10] Rappaz M. Les données générales de la simulation dans le traitement laserLaser de puissance et traitements de matériaux/ published by A.B. Vannes. Romandes: Presses Polytechniques et Universitaires; 1991 pp. 375-401.

[11] Hsu HC, Chakravortys S, Mehrabian R. Rapid melting and Solidification of a surface Layer. Metall. Mater. Trans.B 1978;9:221-9.

[12] Hsu HC, Kou S, Mehrabian R. Rapid melting and Solidification of a surface due to a stationary heat flux. Mater. Trans. B 1980;11:29-38.

[13] Bing-Wu GU, Tian-Chi MA, Brown SK. Three dimensional numerical model for laser transformation hardening of metals. Mater. Sci. Technol. 1994;10: 425-30.

[14] Bahtaoui C, Contribution à la modélisation du comportement thermique des composites chrome/aluminium et nickel/ acier 1018 soumis à des flux impulsionnels: Les transferts de matière induit, PHD, Angers ; 1995.

[15] Chan CL, Mazumder J, Chen MM. Three dimensional axisymmetric model for convection in laser-melted pools. Mater. Sci. Technol. 1987:3:306-11.

[16] Kreutz EW, Pirch N. Melt dynamics in surface processing with laser radiation: Calculations and Applications- Laser de puissance et traitements de matériaux/ published by A.B. Vannes. Romandes: Presses Polytechniques et Universitaires; 1991 pp. 535-555.

[17] Chan CL, Mazumder J, Chen MM. A two dimensional transient model for convection in laser melted-pool. Metall. Mater. Trans. A 1984;15:2175-84.

[18] Basu B, Srinivasan J. Numerical study of steady state laser melting problem. Int. J. Heat Mass transfer 1988;31:2331-8.

[19] Galerie A, Pons M, Caillet M. Elaboration d'alliages de surface sous irradiation laser. Mater. Sci. Eng 1987;88:127-34.

[20] Carlaws HS, Jaegger JC. Conduction of heat in solid. 2nd edition Oxford: Clarendon Press; 1959

[21] Pons M, Caillet M, Galerie A. La boruration superficielle du fer par faisceau laser. Matériaux et Techniques 1985:699-708.

[22] Steen PH, Ehrhard P, Schüssler A. Depth of melt-pool and heat-affected zone in laser surface treatements. Metall. Mater. Trans. A 1994;25:427-35.
[23] kous S. Welding, glazing, and heat treating- A dimensional analysis of heat flow. Metall. Trans. A 1994;13:363-71.

[24] Lax M. Temperature rise induced by a laser beam. J. Appl. Phys 1977;48:3919-24.

[25] Cline HE, Anthony TR. Heat treating and melting material with a scanning laser or electron beam. J. Appl. Phys 1977;48(9):3815-900.

[26] Nissim YI, lietoila A, Gol RB. Temperature distribution produced in semiconductors by a scanning elliptical or circular cw laser beam. J. Appl. Phys 1980;51(1):274-9.

[27] Shercliff HR, Ashby MF. The prediction of case depth in laser transforamtion hardening. Metall. Trans. A 1991;22:2459-65.

[28] Picasso M, Marsden CF, Wagniere JD, Frenk A, Rappaz M. A simple but realistic model for laser cladding. Metall. Mater. Trans. B 1994;25:281-91.

[29] Toyserkani E, Khajepour A, Corbin S. 3-Dfinite element modeling of laser cladding by powder deposition: Effects of powder feed rate and travel speed on the process. J. Laser Appl 2004;15(3):153-60.

[30] Toyserkani E, Khajepour A, Corbin S. 3-D finite element modeling of laser cladding by powder injection: effects of laser pulse shaping on the process, Opt. Lasers Eng 2004;41:849-67.

[31] Liu J, Li L. Study on cross-section clad profile in coaxial single-pass cladding with a low-power laser. Opt. Laser Technol 2005;37:478-82.

[32] de Oliveira U, Ocelık V, Th. J, De Hosson M. Analysis of coaxial laser cladding processing conditions. Surf. Coat. Technol 2005;197:127-36

[33] Bamberger M, Kaplan WD, Medres B, Shepeleva L. Calculation of Process Parameters for Laser Alloying and Cladding. J Laser Appl 1998;10(1):29-33.

[34] Onwubolu C, Paulo Davim J, Oliveira C, Cardoso A. Prediction of clad angle in laser cladding by powder using response surface methodology and scatter search. Optics \& Laser Technology 2007;39:1130-4.

[35] Lin J, Hwang BC. Clad profiles in edge welding using a coaxial powder filler nozzle. Opt. Laser Technol 2001;33:267-75.

[36] Liu J, Li L. Study on cross-section clad profile in coaxial single-pass cladding with a low power laser. Opt. Laser Technol 2005;37:478-82.

[37] Liu J, Li L. Effects of process variables on laser direct formation of thin wall. Opt. Laser Technol 2007;39:231-6.

[38] Chryssolouris G. Laser Machining: Theory and Practice" (Mechanical Engineering Series). Springer-Verlag, Berlin and Heidelberg GmbH \& Co. K; 1991. May.

[39] Chryssolouris G, Zannis S, Tsirbas K, Lalas C. “On laser cladding”. CIRP Journal of Manufacturing Systems 2003;32(6).

[40] Salonitis K, Stavropoulos P, Stournaras A, Chryssolouris G, Thermal Modelling of Laser Cladding, (LANE 07), 5th International conference on laser assisted net shape engineering, Erlangen, Germany; 2007. p.825-35.

[41] El Cheikh H, Courant B, Hascoët J-Y, Guillén R, A thermal analytical model for Direct Laser Fabrication taking notice of the clad geometry, PM2010 World Congress, Florence, Italy.

[42] Lin J. A simple model of powder catchment in coaxial laser cladding. Opt Laser Technol. 1999;31:233-8.

[43] Harris JW, Stocker H, Segment of a circle., In: Handbook of mathematics and computational science. New York: Springer-Verlag; 1998. p. 92-3. 